\title{
Root Rot of Balloon Flower (Platycodon grandiflorum) Caused by Fusarium solani and Fusarium oxysporum
}

\author{
Chi Sung Jeon ${ }^{1}$, Gyoung Hee Kim ${ }^{1}$, Kyeong In Son ${ }^{1}$, Jae-Seoun Hur ${ }^{2}$, Kwon-Seok Jeon ${ }^{3}$, Jun-Hyuck Yoon ${ }^{3}$ \\ and Young Jin Koh ${ }^{1 *}$ \\ ${ }^{1}$ Department of Plant Medicine, College of Life Science and Natural Resources, Sunchon National University, Suncheon 540-950, \\ Korea \\ ${ }^{2}$ Department of Environment Education, College of Education, Sunchon National University, Suncheon 540-950, Korea \\ ${ }^{3}$ Southern Forest Resources Research Center, Korea Forest Research Institute, Jinju 660-300, Korea \\ (Received on July 31, 2013; Revised on September 3, 2013; Accepted on September 6, 2013)
}

Balloon flower (Platycodon grandiflorum) is a kind of mountain herbs whose roots have restorative properties and the cultivating acreage of balloon flower has been steadily increasing in Korea. More frequent rain and high amount of rainfalls as a result of climate changes predisposed balloon flower to the outbreaks of root rot at high-density cultivation area in recent years. Root crowns were usually discolored into brown to blackish brown at first and the infected plants showed slight wilting symptom at early infection stage. Severely infected roots were entirely rotted and whole plants eventually died at late infection stage. The overall disease severities of root rot of balloon flower were quite variable according to the surveyed fields in Jeonnam, Gyeongnam and Jeju Provinces, which ranged from $0.1 \%$ to $40 \%$. The root rot occurred more severely at the paddy or clay soils than the sandy soils and their severities were much higher at lowland than upland in the same localty. The disease increased with aging of the balloon flower. The causal fungi were identified as Fusarium solani and $F$. oxysporum on the basis of their mycological characteristics. The optimum temperature ranges of their mycelial growths was found to be $24^{\circ} \mathrm{C}$. The pathogenic characters of $F$. solani and $F$. oxysporum treated by artificial wounding inoculation on healthy roots of balloon flower revealed that $F$. solani was more virulent than $F$. oxysporum. This study identified the causal agents of root rot of balloon flower as Fusarium solani and $F$. oxysporum, probably for the first time.

Keywords : balloon flower, Fusarium solani, F. oxysporum, root rot

Balloon flower (Platycodon grandiflorum) is a kind of mountain herbs whose roots have restorative properties. As

\footnotetext{
*Corresponding author.

Phone) +82-61-750-3865, FAX) +82-61-750-3208

E-mail) youngjin@sunchon.ac.kr
}

the cultivating acreage of balloon flower has been steadily increasing in Korea, several diseases such as bacterial bud blight, leaf spot, anthracnose, damping-off, Fusarium wilt, leaf spot, stem rot, Sclerotinia rot and blossom rot have been reported in the cultivation fields of Korea (Korean Society of Plant Pathology, 2009). Recently, wilted or blighted balloon flower caused by root rot occurred frequently at high-density cultivation fields and more frequent rain and high amount of rainfalls as a result of climate changes predisposed balloon flower to the outbreaks of root rot in recent years. Phymatotrichopsis omnivore and Rhizoctonia solani were reported as root rot pathogens on balloon flower in Texas, Connectricut and Pennsylvania, USA (David et al., 1989). Fusarium wilt caused by Fusarium sp. was reported as a similar disease with root rot of balloon flower in Korea (Lee et al., 1991), but the causal agents have not been clearly defined. Therefore, the severities of the disease were surveyed at various cultivation fields of balloon flower cultivated in Jeonnam, Gyeongnam and Jeju Provinces and their causal agents were identified in the study.

Symptoms. The mildly infected plants showed undergrowth or slight wilting symptom at early infection stage but severe infection resulted in wilting of leaves (Fig. 1B) and eventual death of the whole plants at late infection stage (Fig. 1C). Root crowns of infected balloon flower were usually discolored into brown to blackish brown at first (Fig. 1D) and severely infected roots were entirely rotted (Fig. 1E).

Disease severities. Disease severities of root rot of balloon flower were surveyed in 9 farmers' fields in Jeonnam Province, 6 fields in Gyeongnam Province and 1 field in Jeju Province. Since all the severely infected plants showed wilting symptoms, the percentages of diseased plants were evaluated from randomly selected 200 balloon flowers in each field based on wilting symptom of the plants. The overall disease severities of root rot of balloon flower were 

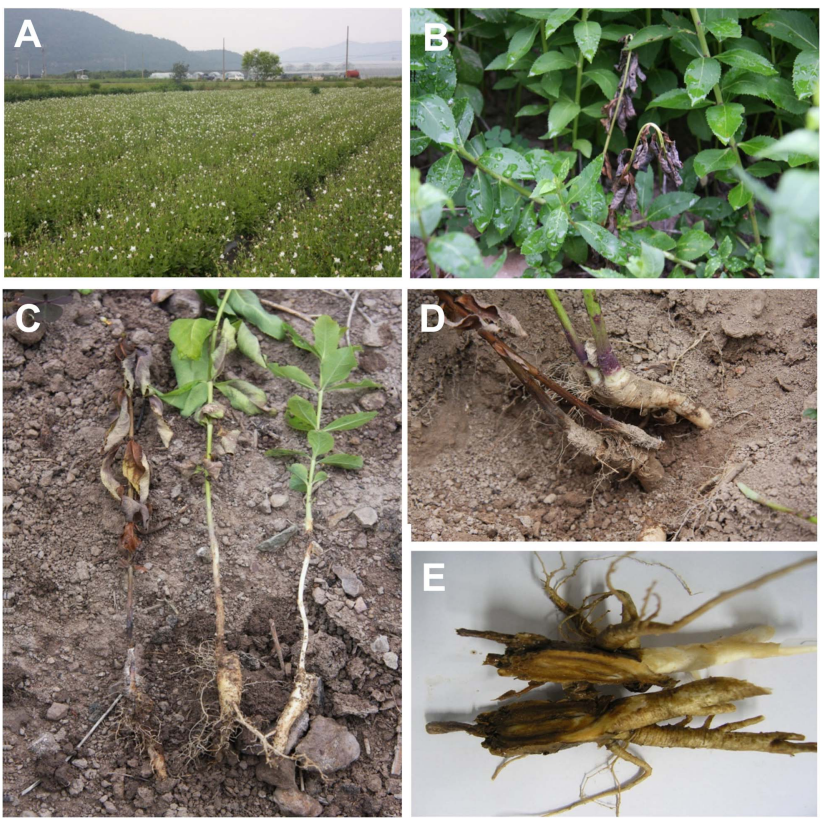

Fig. 1. Symptoms of root rot of balloon flower. (A) Balloon flower field, (B) Wilted plants among the healthy plants, (C) Wilt symptom caused by rotting on root crown of balloon flower, (D) External root rot symptoms, and (E) Internal root rot symptoms.

quite variable according to the surveyed fields, which ranged from $0.1 \%$ to $40 \%$. The root rot diseases occurred more severely at the paddy or clay soils than the sandy soils and their severities were much higher at lowland than upland in the same locality. Poorly drained clay soil was dominant in most of the severely diseased cultivation fields in Jeonnam and Gyeongnam Provinces. However, recent heavy rainfalls during rainy season or typhoon also caused serious outbreaks of root rot in Jeju Province, which were consisted of well drained basalt soil. Excessive soil moisture caused by flooding or poor drainage was known to decay the fibrous roots of many plants because of the reduced supply of oxygen to the roots (Agrios, 2005).

Since balloon flower is one of the perennial root vegetables, the disease was disposed to increase with aging of the balloon flower in the same field. Although one-year-old balloon flower showed low disease severities less than $1 \%$, two-year-old and three-year-old balloon flower showed high disease severities up to $40 \%$, respectively (Table 1). No fungicides were applied in the surveyed fields except two fields in Gyeongnam Province. In the sprayed fields, a fungicide was sprayed one to three times during the growing season of balloon flower and less than $1 \%$ of disease severities were observed. Compared to the spray, $40 \%$ of disease severities were observed in the unsprayed field on badly drained clay soil in the same area. This suggested that root rot of balloon flower might be effectively controlled by proper spray of fungicides. However, no fungicide has been registered as preventative or curative agrochemicals against root rot of balloon flower until now (Korea Crop Protection Association, 2013).

Isolation and identification of the causal agents. Diseased root crown tissues of balloon flower were cut into $5 \mathrm{~mm}$ length and surface-sterilized with $70 \%$ ethyl alcohol for 1 minute and then, placed on potato dextrose agar (PDA)

Table 1. Disease severities of root rot of balloon flower with cultural and environmental conditions on the 16 farmers' fields surveyed in the study

\begin{tabular}{|c|c|c|c|c|c|}
\hline Surveyed date & Surveyed area & $\begin{array}{l}\text { Age of plants } \\
\text { (year) }\end{array}$ & $\begin{array}{c}\text { Acreage } \\
\left(\mathrm{m}^{2}\right)\end{array}$ & $\begin{array}{c}\text { Disease } \\
\text { severities (\%) }\end{array}$ & Remark \\
\hline Jun. 8, 2012 & Seungju, Suncheon, Jeonnam & 2 & 700 & 0.1 & Well drained sandy soil \\
\hline Jun. 8, 2012 & Seungju, Suncheon, Jeonnam & 2 & 600 & 20.0 & Poorly drained clay soil \\
\hline Jun. 12, 2012 & Woosan, Byeolyang, Jeonnam & 2 & 300 & 5.0 & Poorly drained clay soil \\
\hline Jun. 12, 2012 & Jinggwang, Beolgyo, Jeonnam & 2 & 300 & 5.0 & Poorly drained clay soil \\
\hline Jun. 20, 2012 & Yongbang, Gurye, Jeonnam & 2 & 2,600 & 1.0 & Well drained sandy soil on hillside \\
\hline Jul. 2, 2012 & Nakan, Suncheon, Jeonnam & 3 & 1,300 & 20.0 & Flooded clay soil \\
\hline Jul. 4, 2012 & Dodeok, Goheung, Jeonnam & 2 & 160 & 5.0 & Well drained sandy soil \\
\hline Jul. 11, 2012 & Duweon, Goheung, Jeonnam & 2 & 260 & 15.0 & Poorly drained clay soil \\
\hline Jul. 11, 2012 & Duweon, Goheung, Jeonnam & 2 & 400 & 7.0 & Poorly drained clay soil \\
\hline Jul. 16, 2012 & Seonheul, Jocheon, Jeju & 3 & 3,000 & 10.0 & Well drained basalt soil \\
\hline Aug. 10, 2012 & Bukbang, Hadong, Gyeongnam & 2 & 300 & 30.0 & Poorly drained clay soil \\
\hline Aug. 10, 2012 & Danseong, Sancheong, Gyeongnam & 2 & 3,300 & 30.0 & Poorly drained clay soil \\
\hline Aug. 10, 2012 & Mogo, Sancheong, Gyeongnam & 3 & 6,600 & 40.0 & Poorly drained clay soil \\
\hline Aug. 10, 2012 & Sangrim, Geochang, Gyeongnam & 2 & 1,500 & 40.0 & Poorly drained clay soil \\
\hline Aug. 10, 2012 & Sangrim, Geochang, Gyeongnam & 2 & 1,600 & 1.0 & Clay soil, and fungicide sprayed \\
\hline Aug. 10, 2012 & Sangrim, Geochang, Gyeongnam & 1 & 2,600 & 0.1 & Clay soil, and fungicide sprayed \\
\hline
\end{tabular}



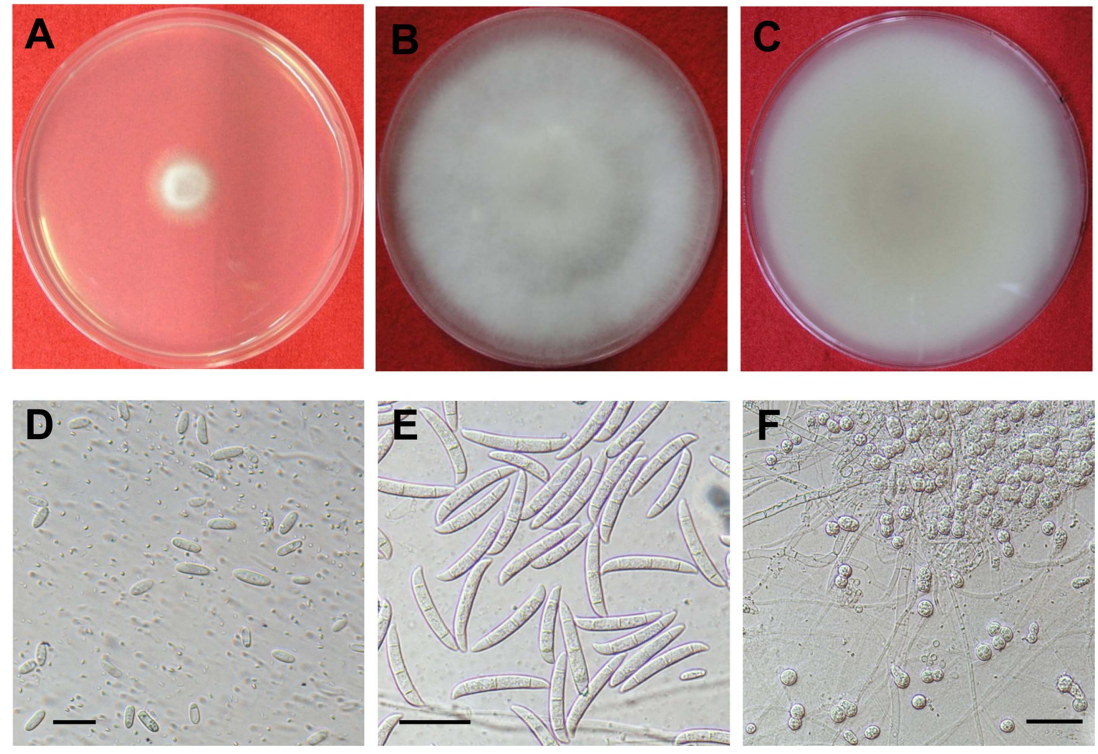

Fig. 2. Morphological characteristics of Fusarium solani. (A) 2-day-old colony on PDA, (B) aerial mycelia of 1-week-old colony on PDA, (C) undersurface of 1-week-old colony on PDA, (D) microconidia, (E) macroconidia, and (F) chlamydospores.

plates at $25^{\circ} \mathrm{C}$ incubator. Mycelial tips of the fungal isolates grown on PDA for 3 days were cut and transferred to fresh PDA. Later on, single spore isolation was conducted on PDA. Morphological characteristics of microconidia of the isolates were examined under the microscope after incubation at $25^{\circ} \mathrm{C}$ for 10 days on PDA. Cultural characteristics of the isolates were examined during incubation on PDA at various temperature conditions. Morphological characteristics of macroconidia and chlamydospores produced on carnation leaf agar (CLA) after incubation for 7 days were also examined under the microscope.

Fusarium spp. were repeatedly isolated from the diseased root tissues of balloon flower. More frequently isolated species formed white aerial mycelia at early growing stage (Fig. 2A) but became pale brown at late growing stage (Fig.
2B, C). The isolates produced abundant microconidia on microconidiophores on PDA (Fig. 2D). Microconidia were oval to ellipsoid measuring 8.1 15.2×3.3 4.3 $\mu \mathrm{m}$ with one or two septa and microconidiophores were monophialide. Macroconidia were inequilaterally fusoid in shape with $3 \sim 5$ septa, and 27.6 41.3×3.5 5.9 $\mu \mathrm{m}$ in size (Fig. 2E) and globose chlamydospores measuring $7.4 \sim 11.2 \mu \mathrm{m}$ were also produced on CLA (Fig. 2F). These mycological characteristics of the species are in accordance with those of Fsarium solani described previously (Booth, 1971) (Table 2). Blast search using 16S rDNA of the isolates confirmed 99\% homology with $F$. solani on NCBI database (Data not shown).

The other species formed white aerial mycelia at early growing stage (Fig. 3A) but became dark purple mycelia at late growing stage (Fig. 3B, C). The isolates produced

Table 2. Comparison of mycological characteristics of the present isolates with Fusarium solani previously described

\begin{tabular}{llcc}
\hline \hline \multicolumn{2}{c}{ Characteristics } & Present isolates & Fusarium solani $^{\mathrm{a}}$ \\
\hline Colony & Color & bluish to bluish-brown & bluish to bluish-brown \\
\hline \multirow{3}{*}{ Microconidia } & Size & $8.1 \sim 15.2 \times 3.3 \sim 4.3 \mu \mathrm{m}$ & $9.0 \sim 16.0 \times 2.0 \sim 4.0 \mu \mathrm{m}$ \\
& Septa & 1 - to 2 -septate & 1 -septae \\
& Shape & cylindrical to oval & cylindrical to allantoid \\
\hline \multirow{3}{*}{ Macroconidia } & Size & $27.6 \sim 41.3 \times 3.5 \sim 5.9 \mu \mathrm{m}$ & $28.0 \sim 42.0 \times 4.0 \sim 6.0 \mu \mathrm{m}$ \\
& Septa & 3- to 5-septate (usually 3-septae) & 3- to 7-septate (usually 3-septae) \\
& Shape & falcate & cylindrical to falcate \\
\hline Conidiophores & & monophialides & $10.0 \sim 11.0 \times 8.0 \sim 9.0 \mu \mathrm{m}$ \\
\hline \multirow{2}{*}{ Chlamydospores } & Size & globose to oval \\
& Shape & globose to oval & and branched monophialides \\
\hline
\end{tabular}

${ }^{\mathrm{a}}$ Described by C. Booth (1971). 

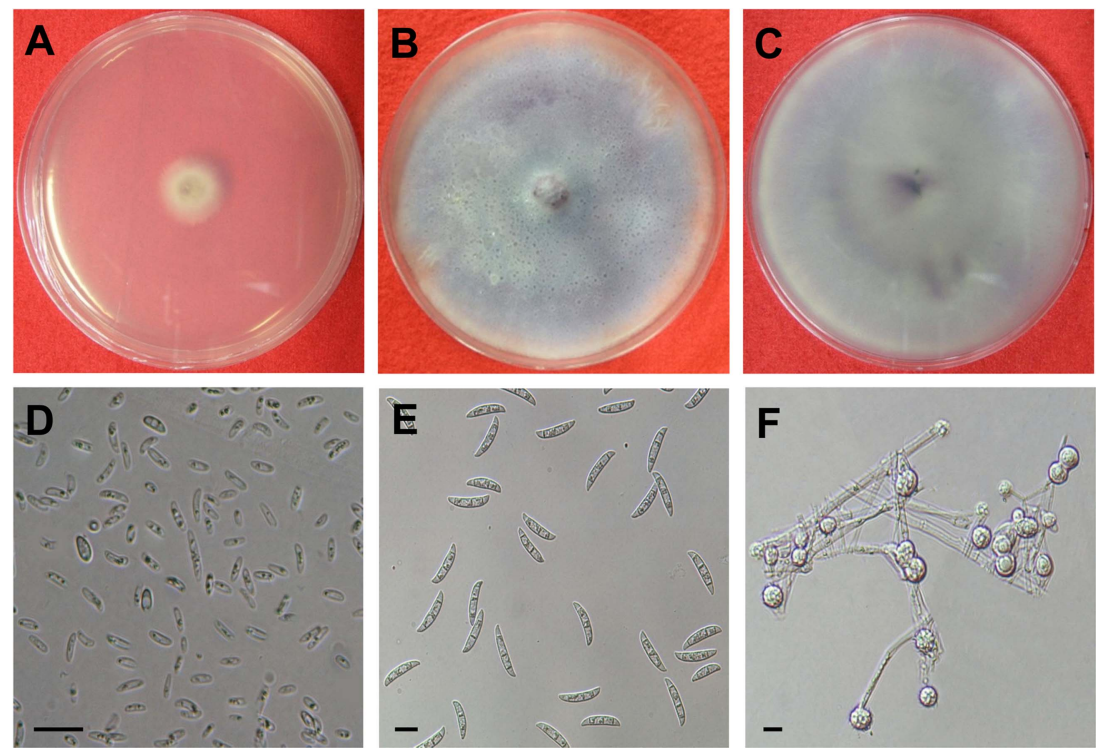

Fig. 3. Morphological characteristics of Fusarium oxysporum. (A) 2-day-old colony on PDA, (B) aerial mycelia of 1-week-old colony on PDA, (C) undersurface of 1-week-old colony on PDA, (D) microconidia, (E) macroconidia, and (F) chlamydospores.

abundant microconidia on microconidiophores on PDA (Fig. 3D). Microconidia were oval to oval to kidney shaped measuring 5.4-14.9×2.0-3.7 $\mu \mathrm{m}$ with usually one septum and microconidiophores were monophialide. Macroconidia were fusoid to falcate in shape with 3 septa, and 21.339.7×3.2-5.4 $\mu \mathrm{m}$ in size (Fig. 3E) and globose chlamydospoes measuring 3.1 12.1 $\mu \mathrm{m}$ were also produced on CLA (Fig. 3F). These mycological characteristics of the isolates are in accordance with those of $F$. oxysporum described previously (Booth, 1970) (Table 3). Blast search using 16S rDNA of the isolates also confirmed $99 \%$ homology with $F$. oxysporum on NCBI database (Data not shown).

Pathogenicity. To prove the pathogenicity of two Fusarium species, the root crowns of balloon flower with or without wound were inoculated with $5 \mathrm{~mm}$ (diam.) mycelia plugs prepared from 7-day-old culture on PDA of each species. The inoculated root crowns were wrapped with plastic film and were maintained in a moist chamber at $100 \%$ relative humidity and $25^{\circ} \mathrm{C}$ for 4 days in the dark. $F$. solani caused typical root rot symptoms on wounded crowns and mild root rot symptoms on unwounded ones (Fig. 4A, B). F. oxysporum caused root rot symptoms only on wounded crowns, but not on unwounded ones (Fig. 4C, D). No symptom appeared on uninoculated crowns with or without wound (Fig. 4E, F). The fungi were reisolated from the lesions of the inoculated roots. Two Fusarium species caused root rot symptoms on wounded crowns and $F$. solani caused much severer root rot than $F$. oxysporum (Table 4). This suggested that $F$. solani was more virulent than $F$. oxysporum. Therefore, it is assumed that $F$. solani might play a

Table 3. Comparison of mycological characteristics of the present isolates with Fusarium oxysporum previously described

\begin{tabular}{|c|c|c|c|}
\hline \multicolumn{2}{|c|}{ Characteristics } & \multirow{2}{*}{$\begin{array}{c}\text { Present isolates } \\
\text { dark purple }\end{array}$} & \multirow{2}{*}{$\begin{array}{c}\text { Fusarium oxysporum }^{\mathrm{a}} \\
\text { dark purple }\end{array}$} \\
\hline Colony & Color & & \\
\hline \multirow{3}{*}{ Microconidia } & Size & $5.4-14.9 \times 2.0-3.7 \mu \mathrm{m}$ & $5.0-12.0 \times 2.2-3.5 \mu \mathrm{m}$ \\
\hline & Septa & 1-septate & 1-septate \\
\hline & Shape & oval to kidney shaped & oval to kidney shaped \\
\hline \multirow{3}{*}{ Macroconidia } & Size & $21.3-39.7 \times 3.2-5.4 \mu \mathrm{m}$ & $27.0 \sim 46.0 \times 3.0 \sim 4.5 \mu \mathrm{m}$ \\
\hline & Septa & usually 3-septate & usually 3 -septate \\
\hline & Shape & fusoid-falcate & fusoid-falcate \\
\hline Conidiophores & & monophialides & monophialides \\
\hline \multirow{2}{*}{ Chlamydospore } & Size & $3.1-12.1 \mu \mathrm{m}$ & $4.0-16.0 \times 4.0-12.0 \mu \mathrm{m}$ \\
\hline & Shape & globose to ellipsoid & globose to ellipsoid \\
\hline
\end{tabular}

${ }^{\mathrm{a}}$ Described by C. Booth (1970). 


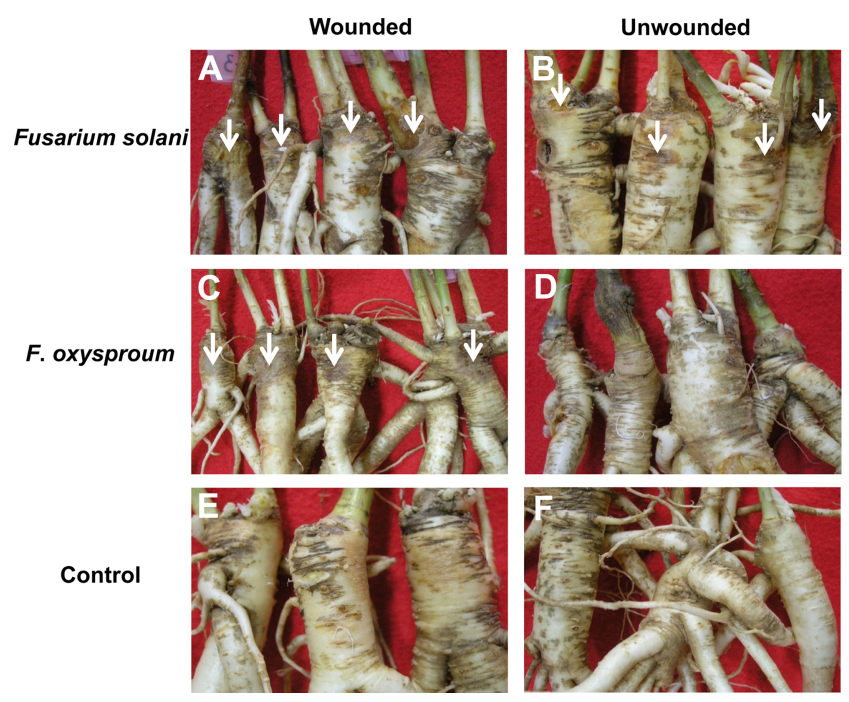

Fig. 4. Root rot symptom development on root crowns of balloon flower artificially inoculated by Fusarium solani and F. oxysporum. (A) wound-inoculated by $F$. solani, (B) unwound-inoculated by $F$. solani, (C) wound-inoculated by $F$. oxysporum, (D) unwoundinoculated by $F$. oxysporum. (E) wounded control, and (F) unwounded control. Arrows indicate soft rot symptoms caused by Fusarium solani or F. oxysporum.

Table 4. Pathogenicity of Fusarium solani and F. oxysporum on root crowns of balloon flower

\begin{tabular}{lcc}
\hline \hline Pathogen & Wounded & Unwounded \\
\hline Fusarium solani & $+++^{\mathrm{a}}$ & + \\
Fusarium oxysporum & ++ & - \\
Control & - & - \\
\hline
\end{tabular}

a +++ : root crowns were discolored and decayed, ++ : root crowns were discolored and softened, +: root crowns were discolored, - : no symptom.

major role in causing the root rot of balloon flower and $F$. oxysporum subsequently infected the diseased roots. This hypothesis is partly supported by the previous finding that $F$. solani was more frequently isolated from root rot lesions than F. oxysporum.

The members of the genus Fusarium are the most important plant pathogens in the world (Booth, 1971). Among them, most of the vascular wilt-causing Fusarium fungi belong to the species of $F$. oxysporum. However, several Fusarium species, primarily $F$. solani and some formae specialis of $F$. oxysporum cause rotting of roots instead of vascular wilts (Agrios, 2005). Although Fusarium wilt was firstly proposed for the disease in Korea by Lee et al. (1991), root rot seems to be more proper term to describe the present disease based on their pathogenesis mechanism as well as the causal fungal complex of $F$. solani and $F$. oxysporum.

Optimum temperature ranges. To investigate optimum

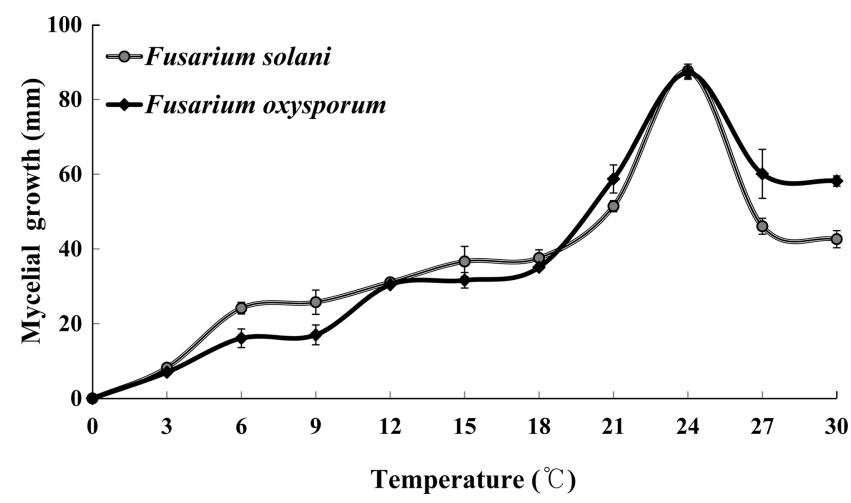

Fig. 5. Effect of temperatures on mycelial growths of Fusarium solani and F. oxysporum, the causal fungi of root rot of balloon flower.

temperature ranges for mycelial growths of the fungi, $5 \mathrm{~mm}$ (diam.) mycelia plugs prepared from 7-day-old culture on PDA of each species were placed on the center of PDA plates. The PDA plates were incubated in 11 different temperature regimes with $3{ }^{\circ} \mathrm{C}$ interval. Mycelial colony diameter was measured 7 days after inoculation on PDA plates. The optimum temperature of mycelial growth of both fungi was found to be $24^{\circ} \mathrm{C}$ as shown in Fig. 5. Although the disease usually occur in July, chemical control should be conducted in May or June in order to efficiently prevent the root rot of balloon flower because the average temperature in late May is approximately $24^{\circ} \mathrm{C}$ in Korea. Moreover, root rot of balloon flower were found to occur severely in badly drained clay soils and the disease severities were also found to be closely related with rainfalls from the field survey data. This suggests that routine control practices such as chemical spray or draining are necessary to alleviate the disease severities of root rot of balloon flower in commonly affected fields during rainy season.

\section{Acknowledgment}

This work was supported by Research Project on Forest Science (FP 0802-2008-06) through the Korea Forest Research Institute (KFRI)'s.

\section{References}

Agrios, G. N. 2005. Plant Pathology. $5^{\text {th }}$ ed. ElsevierAcademic Press, Burlington, MA, USA. 922pp.

Booth, C. 1970. Fusarium oxysporum. CMI Descriptions of Pathogenic Fungi and Bacteria. Kew, Survey, England. No. 211.

Booth, C. 1971. The Genus Fusarium. Commonwealth Mycological Institute. Kew, Survey, England. 237pp..

David, F. F., Gerald, F. B., George, P. C. and Amy, Y. R. 1989. Fungi on Plants and Plant Products in the United States. Academic Press, St. Paul, MN, USA. 1252pp. 
Korea Crop Protection Association. 2012. Agrochemical Use Guide Book. Korea Crop Protection Association. 1351pp.

Korean Society of Plant Pathology. 2009. List of Plant Diseases in Korea. $5^{\text {th }}$ ed. Korean Society of Plant Pathology. 853pp.
Lee, E. J., Lee, Y. H., Cho, W. D., Kim, W. G. and Jin, K. S. 1991. Compendium of Medicinal Plant Diseases with Color Plates. Agr. Sci. Inst., Rural Development Administraion, Suwon, Korea. 210 pp. 